\title{
Workforce Mobility and Innovation Outcomes
}

\author{
Philipp B. Cornelius \\ Rotterdam School of Management, Erasmus University, cornelius@ rsm.nl \\ Bilal Gokpinar \\ UCL School of Management, University College London, b.gokpinar@ucl.ac.uk \\ Fabian J. Sting \\ University of Cologne, Rotterdam School of Management, Erasmus University \\ sting@wiso.uni-koeln.de
}

\begin{abstract}
Employee ideas are a valuable starting point to improve operational efficiency. Organizations therefore systematically tap into employee knowledge. In this paper we empirically investigate how moves between problems and sites affect the innovation value created by employee ideas for the organization. We document that the dynamic effects of problem switches differ fundamentally from the effects of site switches: The innovation outcomes of problem switching employees follow a concave inverse u-shaped pattern, whereas the innovation outcomes of site switching employees follow a convex u-shaped pattern over time. Our findings first contribute to a more fine-grained understanding of workforce mobility and its effects on innovation outcomes. Furthermore, using an evolutionary lens, we develop a search-based framework that coherently explains the dynamics of innovation outcome. We thus contribute to search theory by theoretically linking worker mobility, search behaviour and innovation outcomes.
\end{abstract}

\section{KEYWORDS:}

Employee mobility; employee innovation; search 


\section{INTRODUCTION}

From new products, such as 3M's Post-it notes and Google's Gmail, to more incremental process and product improvements, firms' non-R\&D personnel is an increasingly important source of innovation (Høyrup, Bonnafous-Boucher, Hasse, Lotz, \& Møller, 2012). Their knowledge of firms' existing practices and their day-to-day work environment allow them to easily experiment and come up with new or better processes and products. Driving organisations' innovation is no longer the sole task of dedicated $\mathrm{R} \& \mathrm{D}$ departments, but contributions to innovation are increasingly expected from all employees - from frontline workers to administrators. In highly competitive environments, employee innovation has even become vital to firm survival. The company providing the dataset for this study - a large European automotive supplier operating under significant cost pressure - often initially accepts orders from car manufacturers at a loss. The company then relies on its internal workforce to innovate processes and products in order to break even and generate a profit.

If regular employees are an important source of innovation, firms should manage their workforce in ways that sustain and improve employee innovation in the short and long term. Interfirm employee moves are shown to influence innovation both for the employee as well as for the involved firms (Cirillo, Brusoni, \& Valentini, 2014; Song, Almeida, \& Wu, 2003). In this paper we analyse to the best of our knowledge for the first time intra-firm mobility and its short, medium and long term effects on employee innovation. The interplay between employees' existing knowledge and skills (Madsen, Mosakowski, \& Zaheer, 2003) and the new work environment may improve as well as hamper innovation. We identify two distinct forms of intra-firm mobility, which we call site switching and problem switching. Site switching involves moving from one company location to another (e.g., Delaware to Ohio), while problem switching involves moving from one problem domain to another (e.g., production to component acquisition). 
Previous research has examined implications of worker mobility. However, this work has primarily focused on either inter-firm mobility (Cirillo et al., 2014; Marx, Strumsky, \& Fleming, 2009; Rosenkopf \& Almeida, 2003; Song et al., 2003) or compared internal versus external mobility in terms of their antecedents and consequences (M. Bidwell, 2011; Matthew Bidwell \& Keller, 2014; Matthew Bidwell \& Mollick, 2015; Madsen et al., 2003). Studies that concentrate on intra-firm mobility examine learning and productivity implications of job rotation (Ortega, 2001), its ergonomic effects (Adler, Goldoftas, \& Levine, 1997; Fairris \& Brenner, 2001), rotation and sales performance (Ettlie, 1995) and career outcomes (Campion, Cheraskin, \& Stevens, 1994). Research on innovation implications of worker mobility has remained limited (Ettlie, 1990) and static. We contribute to this research by distinguishing between site and problem switching and analysing the changing impact on employee innovation over time.

A second contribution of our paper comes from a theoretical standpoint. Existing studies on the role of worker mobility on performance highlight two primary theoretical accounts based on employee learning and motivation (Campion et al., 1994; Ortega, 2001). Our results, however, only partially support learning and motivation theories. While the effect of problem switching on innovation outcomes follows a concave pattern over time as predicted by learning and motivation theories, we contrarily observe that site switching follows the exact opposite pattern with a convex relationship. Consequently, we develop a theoretical framework of worker mobility building on evolutionary search theory (Levinthal, 1997; Mihm, Loch, Wilkinson, \& Huberman, 2010; Rivkin \& Siggelkow, 2003) to explain our contrasting findings and reconcile them with learning and motivation arguments. Specifically, we characterize employee innovation after problem switching as search on an entirely new landscape, while after site switching employees face a landscape correlated with the previous site. With this framework we are able to consistently explain the different effects of site and problem switching on innovation outcomes. By explaining long term 
innovation outcomes we also contribute to search theory with a novel account of individual search behaviour (Billinger, Stieglitz, \& Schumacher, 2014).

For this study, we draw on a unique proprietary dataset of an employee idea database of a large European vehicle parts manufacturer. The dataset consists of more than 21,543 ideas submitted by the workforce between 2006 and 2010. Critically, each submitted idea is rigorously evaluated for its financial impact by the accounting department before being implemented. The firm operates in more than ten sites and has a clear organizational structure with specific departments and problem descriptions. In addition, we observe a significant number of location and job switches within the company and see significant variation in terms of employees' idea values both across and within individuals over time.

\section{MOBILITY, LEARNING AND MOTIVATION}

A large body of research based on internal labour markets has focused on explaining how workers' move horizontally and vertically within organizations and examined the mobility process by highlighting factors such as organizational and administrative structures, job ladders, bargaining and career progression (Althauser \& Kalleberg, 1981; Dencker, 2009; DiPrete, 1987; Doeringer \& Piore, 1971; Stewman \& Konda, 1983). Our focus, however, is on innovation performance implications of internal worker mobility, and how these moves thereby may create value for firms. On this front, research on human resource management systems and practices have highlighted job rotation as an important productivity and performance driver (Ichniowski, Kochan, Levine, Olson, \& Strauss, 1996; Ichniowski, Shaw, \& Prennushi, 1997; Ichniowski \& Shaw, 1999). Research on internal mobility of workers has attributed the beneficial individual effects of mobility mainly to two mechanisms: learning and motivation (Campion et al., 1994; Ortega, 2001). 
In addition, worker mobility is a broad concept and there are different types of moves. For instance, Kleinbaum (2012) observes three employees over six years and records their career trajectories. Kellie was an IT specialist and had no mobility during their observation period. Bill was also an IT specialist in a consulting business unit, then moved to the software business unit with a very similar job, but then moved to a very different job, a sales role, in the same unit. Finally, Sheryl had a similar profile to Kellie initially, but then she first moved to an administrative role in the technology consulting unit, a year later to a marketing position in that unit. Later, she moved into a new role in the manufacturing function of the corporate supply chain group at the corporate headquarters. To better disentangle and characterize such variations, we juxtapose two primary types of mobility within organizations, those involving moves between sites (hereafter referred to as site switches) and those involving moves between jobs (hereafter referred to as problem switches).

Individual employees are key enablers within organizations that build and change a firm's knowledge base (Argote \& Ingram, 2000). Internal mobility provides essential experience to these individuals (Campion et al., 1994), since they can typically transport tacit knowledge and skills (Ancona \& Caldwell, 1998; Madsen et al., 2003) albeit in an imperfect way (Dokko, Wilk, \& Rothbard, 2009). Mobility also enhances individuals' human capital (Wexley \& Latham, 2002) and is related to learning and skills acquisition (Campion et al., 1994). A key advantage of mobility is to provide diverse experiences to individuals in a variety of tasks, which is linked to higher performance (Hackman \& Oldham, 1976; Humphrey, Nahrgang, \& Morgeson, 2007; Ichniowski \& Shaw, 1999). For example, Boh et al. (2007) use data from the software industry to show that exposure to related systems is beneficial for performance. (Schilling et al. (2003) show that task variety can improve the learning rate of students playing different versions of a game. Staats \& Gino (2012) use data from a Japanese bank to show that variety promotes workers' productivity. 
In addition, rotation can increase workers' commitment and motivation resulting in improved performance (Fried \& Ferris, 1987; Hackman \& Oldham, 1976; Langer, 1989). Finally, regarding innovation outcomes, mobility and resulting diverse experience promote discovery and generation of quality ideas by providing employees the critical skill of recombining disparate information and alternative ideas from diverse domains (Amabile, 1996; Fleming \& Szigety, 2006; Hargadon \& Sutton, 1997; Taylor \& Greve, 2006).

Considering the temporal nature of learning and motivation effects as a result of mobility, we expect to observe a concave pattern of employees' innovation contributions over time after a job or location switch with the following mechanisms. First, after a problem or site switch, employees will start accumulating experience in the new environment experiencing learning curve effects (Lapré, 2011; Newell \& Rosenbloom, 1981) with opportunities to transfer their existing knowledge and best practices to their new jobs (Ichniowski \& Shaw, 1999; Schmidt, 1975; Tucker, Nembhard, \& Edmondson, 2007). Moreover, they will be highly motivated and engaged with their new jobs or locations (Hackman \& Oldham, 1976; Herzberg, 2003) with increased levels of cognitive stimulation (Langer, 1989). However, this increased innovation performance will slow down after a certain point, as employees will exhaust their original innovative ideas due to cognitive fixation (Bayus, 2013; Jansson \& Smith, 1991; Smith, Ward, \& Schumacher, 1993). In addition, as they become more used to the situation's routines, employees may develop boredom and decreased engagement over time (Fisherl, 1993; Staw, 1980) leading to decreased innovation performance. Thus, considering the existing theoretical accounts based on learning and motivation, we expect to observe a concave pattern of employees' innovation contributions after a problem or site switch over time. 


\begin{abstract}
ANALYSIS
In this section, we analyse employee switching behaviour over time. We also describe the empirical setting in more detail, discuss our econometric approach and give an overview of our main results.
\end{abstract}

\title{
Sample
}

We study the effects of workforce mobility on workers' innovation outcomes at a European car parts manufacturer. The company supplies major worldwide car manufacturers with complex key components as a so-called "first-tier supplier". The company operates in a competitive business environment, which forces it to negotiate close to or below production costs at the time of contract closure. If a contract is won, the company relies on its employees' innovations to continuously reduce production costs and to make a profit. To facilitate idea generation, the company runs an easy to use online database in which employees can enter their ideas. The accounting department then evaluates the ideas in terms of expected cost savings and greenlights ideas for implementation if estimates are good. Employees of all locations around the world submit ideas to improve their respective site and ideas are categorised into five overarching problem areas (below we elucidate the detailed characteristics). We use the accounting department's estimates of idea value and ideas submitted at different sites and in different problem areas to study the effects of site and problem switching on innovation outcomes. The resulting sample consists of 21,543 ideas submitted between 2006 and 2010 by 2,466 employees.

From all submitted ideas we construct a balanced panel of employee-month observations. ${ }^{1}$ This allows us to control for unobservable employee heterogeneity such as ability in a fixed effects model. We also include period dummies to control for seasonality and state of the firm. We

${ }^{1}$ The average tenure at the company is 13 years for frontline workers and first level supervisors (line heads, "Meister", etc.). For all higher management levels, the average tenure is 15 years. 
aggregate all variables per employee-month and estimate the following model of all implemented ideas submitted by employees $i$ during month $t$ :

$$
E C S_{i t}=\beta X_{i t}+\gamma C_{i t}+a_{i}+a_{t}+u_{i t}
$$

where $E C S_{i t}$ is our dependent variable, $X_{i t}$ are our explanatory variables and $C_{i t}$ our control variables as described in the next sections. All variables are aggregated per employee-month.

\section{Expected Cost Savings $\left(E C S_{i t}\right)$}

The dependent variable is expected cost savings of all implemented employee $(i)$ ideas per month $(t)$. There are no rewards for good ideas or punishments for bad ideas, but in our company interviews we learned that employees are intrinsically motivated to submit ideas they deem valuable for the company. Submitted employee ideas are evaluated by the accounting department in terms of expected cost savings over the subsequent three years after the idea's implementation. A mechanistic implementation rule stipulates that every idea with a positive net value contribution (assessed ex ante) should be implemented. Rejected ideas thus are valued at a zero contribution. At the end of each business year, the expected cost savings have to add up with actual accounting data, so we can expect cost savings estimates to be highly accurate. ${ }^{2}$

\section{Site and Problem Switching}

We identify employee site and problem moves by looking at idea submissions at sites or problems the employees have not submitted at before, and we call these "new sites" and "new problems" (from the employees' perspective). The company operates more than ten international sites and has five key problem areas: Acquisition Strategy, Development, Overhead, Product Costs and Production, which allows us to study the effect of problem switching.

\footnotetext{
${ }^{2}$ We exclude correction bookings from the expected cost savings.
} 
New site / problem. To explain immediate effects of site- and problem-switching we look at whether an employee has submitted any ideas at a new site or problem during the current month. Both variables are 1 if this is the case and 0 otherwise.

Months since last new site / problem. To explain long-term effects of switching we examine the number of months since an employee has last submitted an idea at a new site or problem.

By relying on idea submissions to identify moves we may miss out on moves that do not result in any ideas. Since we observe both good and bad ideas, only moves that prevent idea submissions at all are missing in the sample. However, the contextual characteristics of the setting mitigate the theoretical possibility that a switch would abruptly discontinue an individual's ideation activities. First, the company encourages employees to submit all ideas and to leave it to the accounting department to evaluate them. Specifically, there is no punishment for bad ideas. With the idea database described earlier idea submission is also very easy. There is therefore little motivation for employees not to submit ideas, even under time constraints.

Second, we examine the frequency and average value of ideas submitted by employees who start with an idea at the same site and then either submit an idea at a different site or stay at the same site. ${ }^{3}$ In other words, we compare switchers to non-switchers in terms of idea frequency and value. If switching decreased the number of idea submissions (or value), we would expect to see this effect for those employees in our sample who switch. However, employees who switch sites or problems have on average about three times more ideas than those who don't and ideas are comparable in terms of value. This evidence thus supports the notion of increased rather than decreased idea submissions due to switching.

\footnotetext{
${ }^{3} \mathrm{We}$ run the same check for problem switches.
} 


\section{Control Variables}

The fixed effects model allows us to control for employee- and time-fixed effects (such as overall employee ability and state of the firm; see §3.1). Additionally, we control for time-variant employee developments.

Time-variant employee developments could encompass an employee significantly improving their ability to submit good ideas during the term of our study. As a reward, this employee might be sent to a new site or problem; or they might be seen as valuable and so they should help more than one site or problem. In these cases, the reason for the employee's idea value and switching are the same - the employee's improved ability. There are three possible outcomes of employee ability changes: (1) The change has a positive effect on employee idea value and employees submit good ideas before switching. We control for this effect by including variables on the number of successful and rejected ideas previously submitted, the number of successful and rejected ideas submitted during the current month, the number of previous site and problem moves and the number of months since the first idea submitted. (2) The change has a negative effect and employees submit bad ideas before switching. Additionally to controlling for this, a negative effect only makes our results more conservative. (3) There is a change but employees do not submit ideas, which we do not count as a switch.

\section{Results}

In total, the expected cost savings of all ideas in the production problem area amount to about 225 million Euro. This eminently demonstrates the value workforce innovation has for manufacturing companies. It is therefore in companies' interest to foster such innovation by managing their workforce effectively. In the following we look at strategies related to worker mobility which proved most effective at triggering high quality ideas. All numbers are in thousand Euro. 


\section{Insert Tables $1 \& 2$ about here}

It appears worker mobility is a double-edged sword. Site and problem switching exhibit diametric immediate and long term effects. Site switching immediately increases employees' idea values (Model 1: $\beta=326.37, p<.01$ ). Problem switching in Model 1 also increases expected cost savings $(\beta=21.64, p<.05)$. However, this appears to be driven by a more general "newness" effect, as the effect of problem switching when controlling for "newness" in Model 2 (either new site or problem) is negative $(\beta=-266.79, p<.01)$ while site switching maintains a positive effect $(\beta=72, p<.01){ }^{4}$

This becomes clearer when we look at the long term effects of switching. Starting from high immediate returns, site switching has an initially negative trend $(\beta=-3.30, p<.01)$ : The more time elapses since the last site switch, the less valuable ideas become. This is offset in the long term by increasing quadratic returns $(\beta=.08, p<.01)$. Figure 1 depicts the initially negative trend and offsetting quadratic returns of site moves. In turn, starting from negative immediate returns, problem switching has an initially positive trend $(\beta=3.45, p<.01)$ : The more time passes since the last problem switch, the more valuable ideas become. This is offset on the long term by negative quadratic returns from problem switching $(\beta=-.07, p<.01)$. Figure 1 again depicts both trends. We discuss the theoretical implications of these observations in the next chapter.

\section{Insert Figure 1 about here}

\footnotetext{
${ }^{4}$ We include Model 1 and 2 in the results to address potential multi-collinearity concerns with Model 2.
} 


\section{DISCUSSION AND INTERPRETATION}

\section{Learning and Motivation}

Recall that, based on a combined learning and motivation account, one would expect that a worker's value contribution after a move (be it in terms of site or problem) would increase in the short term. This is due to a high level of motivation fostered by the recent move, and the steep learning curve that workers have when starting to operate in new environments: after gaining sufficient understanding the employee will be willing and able to contribute effective innovation ideas. Based on the same theoretical account, one would furthermore expect that the worker's innovation reaches a zenith and then decreases, due to the fact that the motivating impulse of the move sinks into oblivion; and also because learning curve effects level off over time. In fact, this concave u-shaped pattern is what we observe in the time period subsequent to problem switching, as workers increasingly contribute innovation value to the firm in the short term. These contributions reach their maximum in the medium term, and decrease in the long-term. When focussing on moves between sites, we however observe a fundamentally different pattern. Immediately upon switching sites, innovation contributions are substantial. Yet these strong contributions diminish in the medium term, even yielding negative values to the firm (that is, net losses from not-as-good-as-thought innovation initiatives). In the long term, however, contributions of a site-moving worker pick up again, providing considerable innovation outcomes to the firm. Taken together, this convex u-shaped pattern departs from our expectations and is difficult to reconcile with the combined learning and motivation account.

In what follows, we interpret worker mobility and their innovative contributions from a search account. In order to do that, we first have to shape our conceptualization of how a worker's move (either between sites or between problems) plays out within the technology landscape abstraction. 
We shall first interpret how site moves impact a worker's search to form our theoretical account. We then apply the emerging conceptualization to workers' problem switches.

\section{Site Switching and Knowledge Workers' Search}

A site switch of an employee implies that the employee is facing a similar problem in the new site as compared to the previous site. For example, the efficiencies of the two sites' manufacturing processes, which produce identic products, may be improved by accelerating these processes' bottlenecks. It is hence likely that the required improvement actions are also similar. However, there may be slight differences between (i) the sites' problems as well as between (ii) the site's current process configurations. First, process improvement actions in the employee's previous site may not necessarily translate into performance benefits when implemented at the new site, because there are unknown factors (e.g., machine restrictions that impair the acceleration of the bottleneck) as well as random noise (e.g., environmental conditions such as smog impairing production). The switching employee may not immediately be aware of such differences and noise. In terms of the technology landscape abstraction, the technology landscape of the new site is correlated (but not identical) to the employee's previous site. Second, given the different roles and capabilities of plants in global manufacturing networks (Ferdows, 1997), as well as sites' hitherto adaptation to the particular characteristics of their respective environments, the sites may likely have formed different process configurations. For example, even when two initially duplicate sites' problem is to increase efficiency, the site in a lower labour cost country may be better off with less automated processes. Therefore, one can expect that this site's evolution has led to a different configuration than the site with higher labour cost. Likewise, a site that assumes the role of a "lead plant" in the production network may be at the forefront of process innovation (Ferdows, 1997). As a consequence, this site's search trajectory is well ahead of all other sites in the production network. 
When joining a new site, the switching employee can quickly check whether changes experienced or contributed in their previous site have already been carried out at the new site. In doing so, the switching employee can identify improvements in the form of "low hanging fruits" that the new site can implement to rapidly improve process performance. In terms of the technology landscape abstraction, the employee helps the new site climb up a hill in the direction of the steepest ascent. That is, the employee will contribute her best ideas first, because she readily has a robust understanding of the problem. Yet the site-moving employees' value contributions will come to a freeze when all low hanging fruits are reaped. This slows down initially strong performance contributions. In the short term the site switching employee thus may contribute valuable yet decreasing improvements in the medium term.

However, as the employee searches locally, they better understand the commonalities and differences between the new and old fitness landscape, gaining a deeper knowledge of the underlying problem (Gavetti, Levinthal, \& Rivkin, 2005). What is more, the employee understands broader (and potentially remote) areas of the technology landscape, because the configurations of their previous and new site likely differ (Katila \& Ahuja, 2002). The acquired deeper and broader knowledge of the underlying problem encourage the employee to widen their search radius and undertake "long jumps" in the landscape (Fleming \& Sorenson, 2001, 2003). The site-moving employee's propensity to undertake broader search is further bolstered by the diminishing returns that the employee experienced from their recent local search efforts in the medium term (Billinger et al., 2014). However, while long jumps can offer more potential, it is also well-known that they involve higher risk than local search (Chandrasekaran, Linderman, Sting, \& Benner, 2015). Yet the moving employees' long jumps are informed by an enhanced landscape understanding, mitigating their risks. In short, site switching employees broaden they search space as they can rely on a "map of the technology landscape" (Fleming \& Sorenson, 2003). 
To summarize, by conceptualizing a site switch as search on a new but correlated landscape with potentially different starting points, the search account can explain the convex u-shaped pattern via "low hanging fruits" in the short term, freezing local search in the medium term, and broader "long jump" search in the long term.

\section{Problem Switching and Knowledge Workers' Search}

A problem switch implies that the employee faces a new objective, and thus faces an entirely new technology landscape. Given that the new performance objective is a different function of potentially different decisions, there is little correlation or resemblance between the new and the old landscape. For example, decisions to address the objective of efficiency improvement (i.e., the previous problem), may not help or even undermine the objective of quality improvement (i.e., the new objective). Hence, after a problem switch, employees' previous knowledge will likely erode or even become obsolete and so will not allow them to directly contribute valuable improvements. The employee first has to understand how their actions can be mapped into performance results. That is, the employee has to learn about the problem's objective function - as given by the new technology landscape - from scratch (Gavetti \& Levinthal, 2000). Hence the problem switching employee's contributions are low at the beginning. However, the employee's value contributions will increase as the employee begins to search and thereby gradually understands the new objective; that is, they will learn how their improvement ideas translate into measurable benefits according to the new technology landscape. With more search happening, their understanding improves and so do their performance contributions over time. Given their fresh eye on the new problem, they might spot improvements that the employees they joined have left out so far. In the short term, we thus expect an initially low but increasing contribution of the problem switching employee. However, as the employee continues to search locally, the employee's search will reap all possible 
improvement obvious to them. In the medium term, their contributions might thus level-off because of the employee's reliance on local search.

In the long term, the employee might not be able to capitalize on more distant search for two reason: First, they are not encouraged to do so as their recent (medium term) local search still was delivering (small but stable) benefits (Billinger et al., 2014). Second, a problem-switching employee cannot easily carry out broader search in the form of effective long jumps: Their knowledge about the new landscape is too narrow to inform long jumps that would contribute value to the organization (Fleming \& Sorenson, 2001, 2003) - the problem-switching employee only knows the performance landscape in the region around the given technology configuration. They cannot make use of their knowledge about the landscape their previous job was about. So even if there are ideas by the problem switching employee that have long jump character, these ideas are likely to fail. Therefore, we expect that performance contribution of a problem switching employee will further decrease in the long term.

To summarize, by conceptualizing a problem switch as search on a new landscape, the search account can explain the concave inversed $\mathrm{u}$-shaped pattern via improved local search in the short term, slowing local search in the medium term, and freezing local search in the long term. Thus, by distinguishing between site and problem switches as search on a correlated landscape and a new landscape respectively, our landscape conceptualization helps reconcile findings with extant search theory.

\section{CONTRIBUTIONS AND IMPLICATIONS}

Our study makes two main contributions. First, we contribute to the operations management literature by shedding new light on the ongoing debate on "worker mobility" and its benefits (Ichniowski et al., 1996, 1997; Ichniowski \& Shaw, 1999; Staats \& Gino, 2012). We enrich this 
debate by going beyond the hitherto studied static and repetitive settings, and instead focus on a more dynamic context of innovation driven by a company's workforce. We show that the innovation outcomes of worker mobility have an intricate time dimension. This intricacy suggests that operations management researchers and practitioners alike should adopt a more dynamic but also a more fine-grained approach to examine and facilitate intra-firm worker mobility. The latter is because site and problem switches exhibit fundamentally different innovation outcome trajectories over time: in line with the dominant motivation and learning theories on the benefits of job rotation (Campion et al., 1994), we document that a problem switching worker's innovations exhibit a concave inversed u-shaped pattern ensuing her move. However, in contrast to the learning and motivation accounts, we find that a site switching employee's innovation outcomes follow a convex u-shaped pattern.

We second contribute to search theory by viewing problem switches as search on a new (uncorrelated) technology landscape, while conceptualizing site switches as search on a correlated landscape. Particularly, we make a step toward a better understanding of individual search behaviour (Billinger et al., 2014) by linking employees' search behaviour to switches between technology landscapes. We explain the fundamentally different effects of problem and site switches via an intertemporal change in the moving employees' search behaviour. This emerging conceptualization embodies an important building block to search theory because it coherently explains the effects of both problem and site switching to agents' search behaviour. Essentially, problem switching employees are more likely to maintain their local search behaviour on the new landscape. This innovation pattern proves most effective in the medium term but will eventually come to a freeze in the long term (as also predicted by motivation and learning accounts). In contrast, site switching employees will freeze in the mid-term after greedily exploiting local search gains in the form of "low hanging fruits". However, being on a correlated landscape and having 
gained understanding about promising improvements paths as well as regions by making analogies from the previous site's landscape, site switching employees are more likely to undertake broader search in the form of "long jumps". This change in search behaviour will prevent them from freezing in the long term. Rather, their contributed innovation outcomes will increase because of effective broad search.

Our results also have important implications for the practice of operations management. First, problem switching employees are most valuable to the firm in the medium term. Then, the employees know the new problem sufficiently well to contribute innovations but still have a "fresh eye" on solving problems or improving the status quo. For operations managers this implies that the rate of job rotation should be chosen in a way that strikes a commensurate balance within a key trade-off: too many problem switches at a time would hinder learning, too few would freeze improvements. Second, site switching employees are most valuable for the firm immediately after the switch, but also again in the long term. To both reap the low hanging fruits discovered by recently moved employees and to capitalize on the benefits from the more innovative ventures undertaken by expert employees, firms should refrain from imposing too much time pressure right after the switch. Rather, they should provide ample time to facilitate deeper employee understanding and so to benefit from more substantial employee innovations in the long term. Third, given that problem switching yields the strongest outcomes in the medium term while site switching proves most fruitful in the short- and long term, our results also suggest that companies could balance their workforce's innovation outcomes over time by blending problem and site switching. However, in the absence of further analyses, particularly on the interplay between problem and site switching also across employees, this conclusion has to remain speculative. We hope that further research provides answers to this extremely relevant topic. 


\section{REFERENCES}

Adler, P. S., Goldoftas, B., \& Levine, D. I. (1997). Ergonomics, Employee Involvement, and the Toyota Production System: A Case Study of Nummi's 1993 Model Introduction. Industrial and Labor Relations Review, 50(3), 416-437.

Althauser, R. P., \& Kalleberg, A. L. (1981). Firms, occupations, and the structure of labor markets: A conceptual analysis. In B. Furåker (Ed.), Sociological Perspectives on Labor Markets (pp. 119-149). Palgrave Macmillan.

Amabile, T. M. (1996). Creativity in context: Update to "The Social Psychology of Creativity." Westview Press.

Ancona, D. G., \& Caldwell, D. F. (1998). Rethinking team composition from the outside in. In D. H. Gruenfeld (Ed.), Composition. Research on managing groups and teams, Vol. 1. (pp. 2137). Elsevier Science/JAI Press.

Argote, L., \& Ingram, P. (2000). Knowledge Transfer: A Basis for Competitive Advantage in Firms. Organizational Behavior and Human Decision Processes, 82(1), 150-169.

Bayus, B. L. (2013). Crowdsourcing New Product Ideas over Time: An Analysis of the Dell IdeaStorm Community. Management Science, 59(1), 226-244.

Bidwell, M. (2011). Paying More to Get Less: The Effects of External Hiring versus Internal Mobility. Administrative Science Quarterly, 56(3), 369-407.

Bidwell, M., \& Keller, J. (2014). Within or Without? How Firms Combine Internal and External Labor Markets to Fill Jobs. Academy of Management Journal, 57(4), 1035-1055.

Bidwell, M., \& Mollick, E. (2015). Shifts and Ladders: Comparing the Role of Internal and External Mobility in Managerial Careers. Organization Science, (online).

Billinger, S., Stieglitz, N., \& Schumacher, T. R. (2014). Search on Rugged Landscapes: An Experimental Study. Organization Science, 25(1), 93-108.

Boh, W. F., Slaughter, S. A., \& Espinosa, J. A. (2007). Learning from Experience in Software Development: A Multilevel Analysis. Management Science, 53(8), 1315 - 1331.

Campion, M. A., Cheraskin, L., \& Stevens, M. J. (1994). Career-Related Antecedents and Outcomes of Job Rotation. Academy of Management Journal, 37(6), 1518-1542.

Chandrasekaran, A., Linderman, K., Sting, F. J., \& Benner, M. J. (2015). Managing R\&D Project Shifts in High-Tech Organizations: A Multi-Method Study. Production and Operations Management, (online).

Cirillo, B., Brusoni, S., \& Valentini, G. (2014). The Rejuvenation of Inventors Through Corporate Spinouts. Organization Science, 25(6), 1764 - 1784.

Dencker, J. C. (2009). Relative Bargaining Power, Corporate Restructuring, and Managerial Incentives. Administrative Science Quarterly, 54(3), 453-485.

DiPrete, T. A. (1987). Horizontal and Vertical Mobility in Organizations. Administrative Science Quarterly, 32(3), 422-444.

Doeringer, P. B., \& Piore, M. J. (1971). Internal Labor Markets and Manpower Analysis. M.E. 
Sharpe.

Dokko, G., Wilk, S. L., \& Rothbard, N. P. (2009). Unpacking Prior Experience: How Career History Affects Job Performance. Organization Science, 20(1), 51-68.

Ettlie, J. E. (1990). Intrafirm Mobility and Manufacturing Modernization. Journal of Engineering and Technology Management, 6(3-4), 281-302.

Ettlie, J. E. (1995). Product-Process Development Integration in Manufacturing. Management Science, 41(7), 1224-1237.

Fairris, D., \& Brenner, M. (2001). Workplace transformation and the rise in cumulative trauma disorders: Is there a connection? Journal of Labor Research, 22(1), 15-28.

Ferdows, K. (1997). Making the Most of Foreign Factories. Harvard Business Review, (MarchApril).

Fisherl, C. D. (1993). Boredom at Work: A Neglected Concept. Human Relations, 46, 395-417.

Fleming, L., \& Sorenson, O. (2001). Technology as a complex adaptive system: evidence from patent data. Research Policy, 30(7), 1019-1039.

Fleming, L., \& Sorenson, O. (2003). Navigating the Technology Landscape of Innovation. MIT Sloan Management Review, 44(2), 15-23.

Fleming, L., \& Szigety, M. (2006). Exploring the Tail of Creativity: An Evolutionary Model of Breakthrough Invention. Advances in Strategic Management, 23, 335-359.

Fried, Y., \& Ferris, G. R. (1987). The Validity of the Job Characteristics Model: A Review and Meta-Analysis. Personnel Psychology, 40(2), 287-322.

Gavetti, G., \& Levinthal, D. A. (2000). Looking Forward and Looking Backward: Cognitive and Experiential Search Giovanni Gavetti. Administrative Science Quaterly, 45(1), 113 - 137.

Gavetti, G., Levinthal, D. A., \& Rivkin, J. W. (2005). Strategy making in novel and complex worlds: the power of analogy. Strategic Management Journal, 26(8), 691-712.

Hackman, J. R., \& Oldham, G. R. (1976). Motivation through the design of work: test of a theory. Organizational Behavior and Human Performance.

Hargadon, A., \& Sutton, R. I. (1997). Technology Brokering and Innovation in a Product Development Firm. Administrative Science Quarterly, 42(4), 716-749.

Herzberg, F. (2003). One More Time: How Do You Motivate Employees? Harvard Business Review, 81(1), 87-96.

Høyrup, S., Bonnafous-Boucher, M., Hasse, C., Lotz, M., \& Møller, K. (2012). Employee-Driven Innovation: A New Approach. Palgrave Macmillan.

Humphrey, S. E., Nahrgang, J. D., \& Morgeson, F. P. (2007). Integrating motivational, social, and contextual work design features: a meta-analytic summary and theoretical extension of the work design literature. The Journal of Applied Psychology.

Ichniowski, C., Kochan, T. A., Levine, D., Olson, C., \& Strauss, G. (1996). What Works at Work: Overview and Assessment. Industrial Relations, 35(3), 299-333. 
Ichniowski, C., \& Shaw, K. (1999). The Effects of Human Resource Management Systems on Economic Performance: An International Comparison of U.S. and Japanese Plants. Management Science, 45(5), $704-721$.

Ichniowski, C., Shaw, K., \& Prennushi, G. (1997). The Effects of Human Resource Management Practices on Productivity: A Study of Steel Finishing Lines. The American Economic Review, 87(3), 291-313.

Jansson, D. G., \& Smith, S. M. (1991). Design fixation. Design Studies.

Katila, R., \& Ahuja, G. (2002). Something Old, Something New: A Longitudinal Study of Search Behavior and New Product Introduction. Academy of Management Journal, 45(6), 11831194.

Kleinbaum, A. M. (2012). Organizational Misfits and the Origins of Brokerage in Intrafirm Networks. Administrative Science Quarterly, 57(3), 407-452.

Langer, E. J. (1989). Minding Matters: The Consequences of Mindlessness-Mindfulness. Advances in Experimental Social Psychology, 22, 137-173.

Lapré, M. A. (2011). Reducing customer dissatisfaction: How important is learning to reduce service failure? Production and Operations Management, 20(4), 491-507.

Levinthal, D. A. (1997). Adaptation on Rugged Landscapes. Management Science, 43(7), 934950.

Madsen, T. L., Mosakowski, E., \& Zaheer, S. (2003). Knowledge Retention and Personnel Mobility: The Nondisruptive Effects of Inflows of Experience. Organization Science, 14(2), 173-191.

Marx, M., Strumsky, D., \& Fleming, L. (2009). Mobility, Skills, and the Michigan Non-Compete Experiment. Management Science, 55(6), 875-889.

Mihm, J., Loch, C. H., Wilkinson, D., \& Huberman, B. A. (2010). Hierarchical Structure and Search in Complex Organizations. Management Science, 56(5), 831-848.

Newell, A., \& Rosenbloom, P. S. (1981). Mechanisms of skill acquisition and the law of practice. In J. R. Anderson (Ed.), Cognitive Skills and Their Acquisition (pp. 1-55). Psychology Press.

Ortega, J. (2001). Job Rotation as a Learning Mechanism. Management Science, 47(10), 13611370.

Rivkin, J. W., \& Siggelkow, N. (2003). Balancing Search and Stability: Interdependencies Among Elements of Organizational Design. Management Science, 49(3), 290-311.

Rosenkopf, L., \& Almeida, P. (2003). Overcoming Local Search Through Alliances and Mobility. Management Science, 49(6), 751-766.

Schilling, M. A., Vidal, P., Ployhart, R. E., \& Marangoni, A. (2003). Learning by Doing Something Else: Variation, Relatedness, and the Learning Curve. Management Science, 49(1), 39-56.

Schmidt, R. A. (1975). A Schema Theory of Discrete Motor Skill Learning. Psychological Review, 82(4), 225-260.

Smith, S. M., Ward, T. B., \& Schumacher, J. S. (1993). Constraining effects of examples in a 
creative generation task. Memory \& Cognition, 21(6), 837-845.

Song, J., Almeida, P., \& Wu, G. (2003). Learning-by-Hiring: When Is Mobility More Likely to Facilitate Interfirm Knowledge Transfer? Management Science, 49(4), 351-365.

Staats, B. R., \& Gino, F. (2012). Specialization and Variety in Repetitive Tasks: Evidence from a Japanese Bank. Management Science, 58(6), 1141-1159.

Staw, B. M. (1980). The consequences of turnover. Journal of Occupational Behavior, 1, 253-273.

Stewman, S., \& Konda, S. L. (1983). Careers and Organizational Labor Markets: Demographic Models of Organizational Behavior. American Journal of Sociology, 88(4), 637-685.

Taylor, A., \& Greve, H. R. (2006). Superman or the fantastic four? Knowledge combination and experience in innovative teams. Academy of Management Journal, 49(4), 723-740.

Tucker, A. L., Nembhard, I. M., \& Edmondson, A. C. (2007). Implementing New Practices: An Empirical Study of Organizational Learning in Hospital Intensive Care Units. Management Science, 53(6), 894-907.

Wexley, K. N., \& Latham, G. P. (2002). On-site training methods. In Developing and Training Human Resources in Organizations (pp. 167-209). Prentice Hall. 
TABLE 1

OLS Regressions of Expected Cost Savings with Employee Fixed Effects ${ }^{\mathrm{a}, \mathrm{b}}$

\begin{tabular}{|c|c|c|}
\hline \multirow[b]{2}{*}{ Variables } & \multicolumn{2}{|c|}{ Expected Cost Savings $\left(E C S_{i t}\right)$} \\
\hline & Model 1 & Model 2 \\
\hline New site & $326.37 * * *(10.86)$ & $72.00 * * *(19.73)$ \\
\hline New problem & $21.64 * *(9.36)$ & $-266.79 * * *(20.90)$ \\
\hline New site/problem & & $353.71 * * *(22.92)$ \\
\hline Months since last new site & $-3.34 * * *(0.63)$ & $-3.30 * * *(0.63)$ \\
\hline Months since last new site ${ }^{2}$ & $0.08 * * *(0.02)$ & $0.08 * * *(0.02)$ \\
\hline Months since last new problem & $3.49 * * *(0.51)$ & $3.45 * * *(0.51)$ \\
\hline Months since last new problem ${ }^{2}$ & $-0.07 * * *(0.01)$ & $-0.07 * * *(0.01)$ \\
\hline Months since first idea & $-0.03(0.12)$ & $-0.02(0.12)$ \\
\hline \# of prev. suc. ideas & $-0.18(0.16)$ & $-0.14(0.16)$ \\
\hline \# of prev. failed ideas & $-0.21 *(0.11)$ & $-0.20 *(0.11)$ \\
\hline \# of site switches & $35.94 * * *(2.72)$ & $35.01 * * *(2.71)$ \\
\hline \# of problem switches & $-28.72 * * *(2.84)$ & $-28.51 * * *(2.83)$ \\
\hline \# of successful ideas & $51.94 * * *(0.92)$ & $51.16 * * *(0.92)$ \\
\hline \# of failed ideas & $-4.61 * * *(0.27)$ & $-4.69 * * *(0.27)$ \\
\hline Year-Month Dummies & Yes & Yes \\
\hline Employee Fixed Effects & Yes & Yes \\
\hline Constant & $5.27(4.03)$ & $5.47(4.03)$ \\
\hline F-Stat & 92.34 & 94.91 \\
\hline $\mathrm{R}^{2}$ & 0.05 & 0.05 \\
\hline$N$ & 118,368 & 118,368 \\
\hline Employees & 2,466 & 2,466 \\
\hline
\end{tabular}

TABLE 2

Descriptive Statistics

\begin{tabular}{lrrrr}
\hline Variables & Mean & Std. Dev. & \multicolumn{1}{c}{ Min } & \multicolumn{2}{c}{ Max } \\
\hline Expected Cost Savings $\left(E C S_{i t}\right)$ & 6.76 & 206.07 & $-10,988.93$ & $29,443.89$ \\
New site & 0.00 & 0.06 & 0.00 & 1.00 \\
New problem & 0.00 & 0.07 & 0.00 & 1.00 \\
New site/problem & 0.01 & 0.08 & 0.00 & 1.00 \\
Months since last new site & 1.00 & 4.78 & 0.00 & 47.00 \\
Months since last new problem & 1.68 & 6.16 & 0.00 & 49.00 \\
Months since first idea & 12.11 & 13.86 & 0.00 & 59.00 \\
\# of prev. suc. ideas & 2.29 & 8.40 & 0.00 & 278.00 \\
\# of prev. failed ideas & 3.00 & 17.35 & 0.00 & 761.00
\end{tabular}


\# of site switches

0.74

0.77

0.72

0.00

7.00

\# of problem switches

0.09

0.72

0.00

5.00

\# of successful ideas

0.74

0.00

67.00

\# of failed ideas

0.09

2.50

0.00

737.00

\section{FIGURE 1}

Predicted Cost Savings $\left(E C S_{i t}\right)$ by Months Since Last Switch

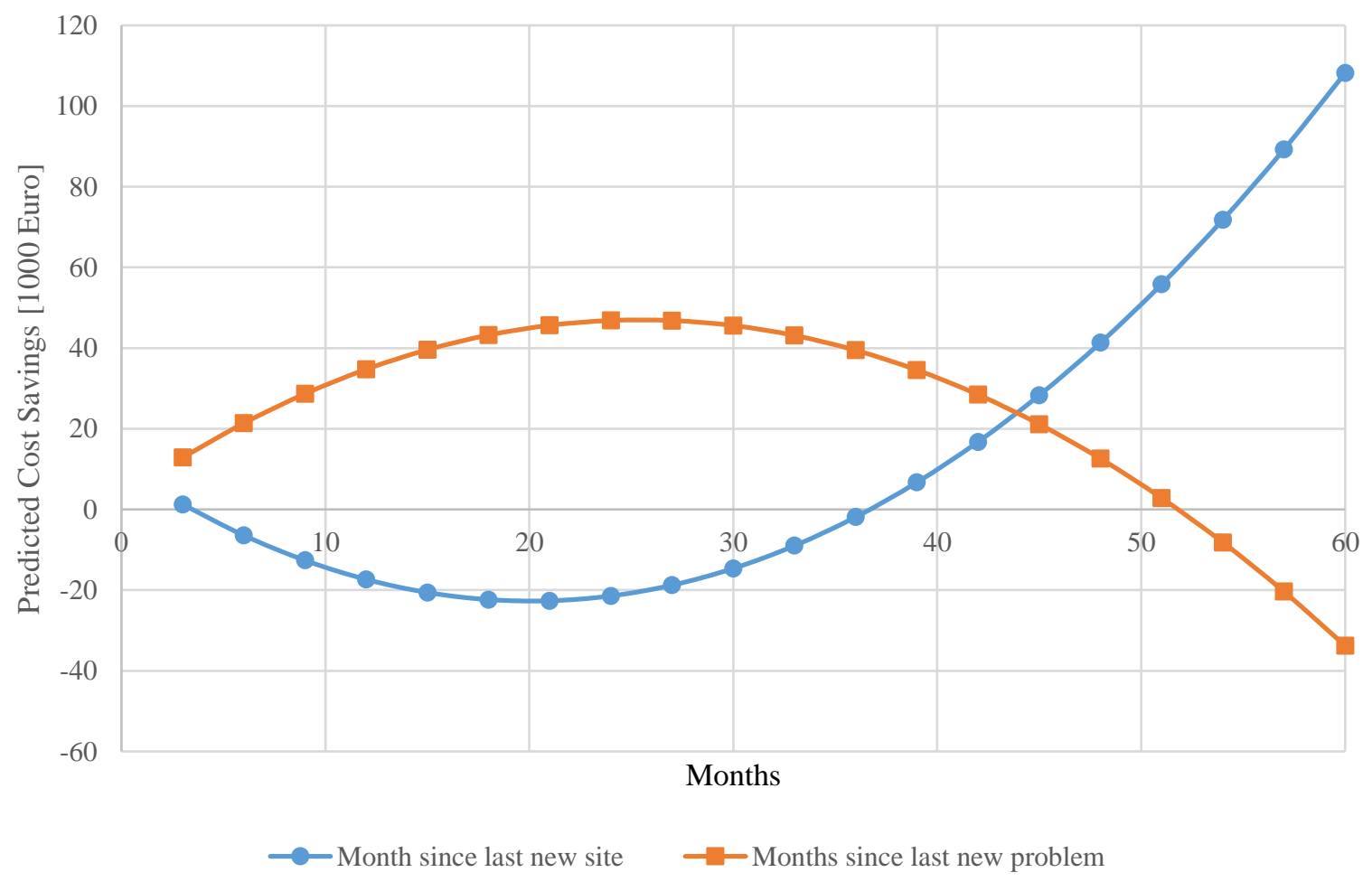

a All other variables at their means. 